was no growth to be removed, henee, no operation having been done, only a diagnosis has beell made.

Other instruments, sueh as curette and foreeps, aud even the finger, are not worthy of eomparison with the odenotome. I can aeeount for its not being in general use only on the luypothesis that Dr. Gradle's book las not been read generally, and, so far as I know, no one has written about it in the journals. Wishing to know how mucil the instrument is valued by its inventor, after the lapse of several years, I addressed lim a letter a few days ago, to whieh I received the following reply: "Since the last eight years I have used my instrument exelusively for adenoid operations in primary cases. It is quite exceptional that I find any remnants after operation-perhaps in five per eent.-and these are usually insignificant. The pain is so slight and transient that $I$ find nareosis unneeessary. All colleagues who have spoken to me about their experienee with my instrument, eonfirm my experience. I have, however, seen no published record of others." Dr. Gratle has not spoken too highly of his adenotome, nor has he overstated his suceesses. 


\title{
DIAGNOSIS OF SARCOMA.
}

\author{
BY W. A. BRYAN, A. M., MI. D., NASHVILLE, TENN.
}

\section{(Continued from September Number.)}

Passing to the sccond division of the subject, the discussion will be confined to a differentiation between sarcomata and those swellings which are most likely to confuse the diagnostician. Here, again, the lines are not and cannot be drawn clearly and unmistakably by clinical methods, aside from the microscope; so that if the very fact that doubt does cxist can be used to arouse suspicion of malignancy in these border-line cases, the purpose of the writer will be well accomplished.

In reviewing the literature and in attempting to recall the cases where I have seen mistakes made over sarcomata, it appears that thc differentiation is difficult between sarcoma and carcinoma, sarcoma and gumma, sarcocoma and tubercular swellings, probably more frequently than in other cases. Yet the fact that certain benign tumors develop rather rapidly and certain sarcomata develop slowly and conceal the evidence of malignancy renders it necessary to consider certain of the benign tumors in this connection, especially fibroids, chondroma, osteoma, and adenoma, particslarly, if it be of thyroid origin.

Great stress is laid in our teaching on the diffcrence between sarcoma and carcinoma; too much stress, perhaps, since it is usually donc to the neglcct of diffcrentiating these growths from benign conditions and the advice in casc of a malignant growth is the same, if scen early enough, and impcrative, but the delay of uncertainty between malignant and benign growths often results fatally. Sarcoma is on an avcrage a larger tumor than carcinoma, yet to await this means of diagnosis is little less than criminal. Sarcoma grows more rapidly than carcinoma, except in the enceph- aloid variety of the latter. The situation-I speak only of primary growths-of sarcoma; since it is of mesoblastic origin, is not connected with epithelial tissues, but arises invariably from connective tissue, and so is situated more deeply than cancers are, and originates in histological regions that have no glandular or tegumentary tissue; while cancers originate in structures that contain epiblastic or hypoblastic tissue. In those glands containg large amounts of connective tissue, sarcoma or carcinoma either may arise. I would not be misunderstood to mean that sarcoma is always deep under the integument even in its incipiency, for it is often found in the skin, sometimes in or immediately beneath the mucous membrane. That sarcoma is the malignant tumor of youth and carcinoma that of old age is no longer tenable; for cancers appear now and then in the young, rarely, but sarcomata are frequent in the old, and may be found at any age, though varying with age in their predilection for certain organs, as will be shown later. When the number of individuals under 30 years' old and those over that age is considered, it is doubtful to my mind if the percentage of sarcomata is any greater in the young than in the old. Since writing the first part of this article, I have seen a sarcoma of the right labium majora in a woman $5^{6}$ years' old, and one of the foot in a man aged 46 (see Figs. 7 and 8). These alone prove nothing, but taken in connection with the average age given before, they do not change it considerably.

Sarcoma is often encapsulated seemingly at its beginning (see Fig. 7), and carcinoma is not unless it starts as a benign growth. Hence, 
in a question between the two early in their development the more movable it is the more probably it is sarcoma. Sarcoma has but litthe connective tissue; carcinoma has mucli; one might say that the connective tissue of early sarcoma is outside of it, in a capsule, and that of carcinoma is inside of it acting as stroma, hence early one is substantially isolated from the surrounding structures, while the other is connected directly with the surrounding connective tissue. Therefore, retraction of the nipple and Halstead's sign are in evidence in carcinoma of the breast; in sarcoma they are not. It may be put this way, that sarcoma has a greater tendency to push other tissues aside, and carcinoma to bind them into one mass. Involvement of the lymph-nodes is a classic sign of carcinoma, and in sarcoma, unless in the testicle or ton$\mathrm{sil}$, it is rarely seen. This evidence of lymphatic invasion is very valuable, when present, from a standpoint of diagnosis, but is sadly late for its unfortunate host, and one would suppose that no physician had his patient's interest so little in view as to await such information. The sudden enlargement of the tumor, due to concealed hemorrhage in the tumor substance, dilation of the veins in the skin overlying large sarcomata, the formation of cystic accumulations in the tumor tissue are common in sarcoma, and are rare in cancer. Ulceration and hemorrhage, plus saphrophytic, and maybe pathogenic, infection, with the associated loss of fluids and increased progress of cachexia are seen oftener in cancer, -while pigmentation and association of malignant elements with the various benign tumors is found in sarcoma. Metastases remote from the primary focus are more likely to be found in sarcoma, just as those situated close to it, but out of the line of the lymphatics, indicate a similar conclusion. When large a globular or spindle-shapcd tumor is much more likely to be of mesoblastic origin.

Gumma las probably been confused with sarcoma much more frequently in the past than will happen again. So true is this that I have a dissertation, read in 1893 by Heinrich Meliler on the treatment of sarcoma with potassium iodide. In this paper Melhler boldly takes the stand that a considcrable number of mesoblastic malignant tumors are amenable to anti-syphilitic treatment for tertiary lesions, and quotes extensively from other authorities to substantiate his conclusions. This vicw has been expressed often, and even yet some hold that malignancy is either a more or less remote result of syplilitic poison or a twin sister to the tertiary lesions, especially gummata, of syphilis.

Syphilis is much better treatcd now than formerly, so that likely some considerable percentage of physicians never saw a gumma. The fact that the patient has had syphilis should lead one to suspect gumma if a tumor presents, this all the more if it can be shown that treatment was inadequate; that treatment of syphilis is often inadequate, any one who is called upon to observe large numbers of cases in the practice of large cities is prepared to corroborate, largely, it appears, from negligence on the part of patients, rarely to hasty treatment with imperfect diagnosis. Confirmatory signs should be sought to sustain a diagnosis of gumma. If still doubtful the visest course is to call the aid of the microscope; it is no larm to investigate a gumma; it is frightful to neglect a sarcoma. If the mass be so situated as to preclude the employment of surgery, or where one cannot gct a piece for section, then the therapcutic test should be administered rigorously. Let me repeat, to decide between gumma and sarcoma is difficult; syphilitics may have sarco$\mathrm{ma}$; the therapeutic test is a good one, but in case the tumor is sarcoma, does no good and causes the patient to sit the time of such treatment beneath a sword of Damocles that may fall at any moment, and send metastases through his vessels silently but as sure of a 
fatal end as that it has been allowed to pass some unknowable second, that marks the boundary between enrable and incurable sarcoma. The best index to one's ignorance of tmors is the time he advises them "to wait and see." Ileal results even with our present imperfeet knowledge cannot be hoped for until there sliall issule from the lips of every physician who sees a suspicions tumor "now is the accepted time; today is the lay of salvation."

More of my mistakes in cliagnosis of swelling have been between tubereular processes
Calmette's ophthalmo-reaction is very simple in application, as its use has extended, there are a considerable number of damaged eyes reported, and so either the cutaneous or hypodermic administration of tuberculin will likely remain as the safest and most reliable tests for obscure tubercular lesions. I operated on a young man a year ago who had been advised by good physicians to lave an amputation above the knee for a sarcoma in the upper end of the tibia. He was given tuberenlin, to which lie promptly reacted, and the bone was

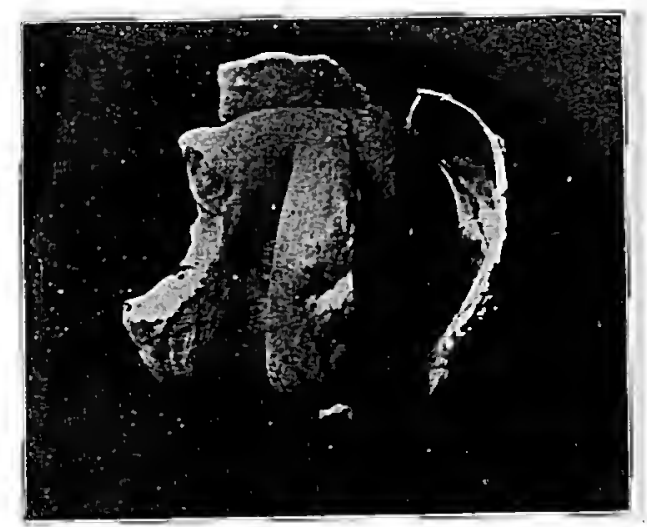

Ficte FicezF 7.-X/sxo-sarcoma of labrium majus in The capsule has been dissected back for demonstration.

and sarcomata, when arising from bone or periosteum. This can now be disposed of easily and surely by the use of tuberculin, which is very positive when used on twbercular subjeets. Failure is possible in one way, namely, if there shoukl be tuberculosis and sarcoma both present in the same individual. The reaction to tuberculin does not require niany days, as a rille not over two or three, and as a limb is usually at stake, tuberenlin should never be forgotten in donbt between these two. It may not be amiss to observe here that though opened, the pus and carious tissne removed, leaving him a good leg. The use of tuberculin is so simple and so reliable that it shonld be used in all doubtful differentiations, not only between these two, but to distinguisl tuberculosis from any other deceptive lesion. Fibroids are to be differentiated from sarconvata if possible; for it is impossible in many cases to say clinically whether a tumor is fibroma or sarcoma. It is furthermore impossible to say that any fibroid, however benignly it may behave today, lhas not actively growing 
sarcomatous cells in its substance. Hence the futility of advising patients to carry fibroids "in as nuch as they will cause no harm, and in as much as they will likcly disappear later in life." There is no such thing as being positive that any fibroid is harmless, or that it will not become inalignant, or that it is not already. malignant, or that it will disappear ever. The odds are a thousand to one against disappearance. This statement sounds pitifully absurd and needless, yet twice in the last two months las the statemient been niade to me by women that their physicians liad diagnosed tumors and insisted upon leaving them alone; :for they would disappear at the climacteric." One of these women following this blunder conficlently, was operated for a large sarconna ten years afterward (see Fig. 3), and the cther having similar confidence in her plyysician, now, two years after the advice, is the host of an inoperable uterine caneer. Whose fault is it? We may insist upon application of the elassieal differentiation, between benign and maliguant tumors to the specific case in hand, and say that the fibroid grows slowly; does not infiltrate, does not produce metastases or emaciation, while sarcoma does produce all these and nore; that the former grows slowly and the latter does not. This is all very true so far as it goes, but so long as men rely on it and advise one way for one side and another for the other side, so long will the surgeon return enormous percentages of recurrences in his statistics and be embarrassed by the censure, so readily bestowed, that if the tunnor had not been operated on it would likely not have "scattered." There are extremes on either side, where one can be absolutely certain that this tumor is malignant, and fairly certain that that one is not, but as we come nearer the border between the two, the lines of differentiation facle and it is lopeless to tell the difference. The more zealons one has been in one's study of tumors and the more one has considered the operative results, the more that one becomes sure not of infallible powers of diagnosis, but of the fact that a fair deal to the patient can be done only where he is advised to have the safest, the most conservative treatment while there is yet time.

Again, we may notice the evidences indicating that a fibroma lias assumed a malignant form. The statements are trine-for other benign tumors as well. The appearance of rapid growth in a tumor that has been growing slonly for a long period ot time or had long ago ceased to show signs of growth, is very significant and if another positive explanation of this increase cannot be given, it becomes practically a certainty that the cliange is due to malignancy. If at the same time the consistency of the thmor changes and it becomes softer as it grows larger, this favors malignaney. In ease of fibroids of the uterus the tumor becoming maliguant nua not grow alone, but the uterus may enlarge so rapidly and beconle so soft as to render a suspicion of-pregnancy highly probable unless the evidence against pregnancy or in favor of malignancy can be made positive. I saw one of America's most brilliant surgeons "back out" from an abdomen recently in a case of this kind, preferring to await a microscopical section to justify him in operating later or refrainur from it. His words were, "There are only two conditions capable of proilucing rapid enlargenent and softening of a nterus bearing fibroids; one is pregnancy, the other is malignant clange." It inust be borne in mind that where multiple fibroids are present or where mnlti-lobulated tumors are concerned the changes of tumor tissue due to inalignancy do not occupy the whole mass necessarily, but confine themselves to the parts involved.

In those cases having suspicions tumors of the lower jaw there is a danger of mistaking an odontoma, of which there are several varieties. So that it becomes necessary to bear in mind that such mistakes have been made re- 
sulting in excision of the mandible for what proved too late to be an innocent tumor or a cyst. Attention sliould be called to the fact that both tumors, especially those likely to be eonfused with sarconiata are apt to have a history of an unerupted tooth at or near the site of tumor formation; that this tumor is likely to reveal the presence of tooth tissue in its substanee if punetured by a sharp steel needle; that odontoma is very unlikely to grow as rapidly as sarcoma does; that it is more probable in that part of the jaw that gives origin to the tooth tissue; that it does not if left alone infiltrate and produce seeondary growths, and that if the nature of the growth is still not elear a skiagraph will likely show the presenee of the abnornally situated tooth or teeth. In ease of unecrtainty yet, a section must be nracle for the microscope.

Aneurysm may usually be distinguished with ease, provided a clear listory can be obtained. A pulsating sarcoma situated over the course of a large blood vessel may cause confusion. The age of the patient, the condition of the arteries, the absence of a lesion likely to cause aneurysm, the irregularity of the slape or surface of sarcoma, and the uneven density of its sur face, together with the pulse signs, viz.: delayed pulsation distal to the tumor, enlargement of the tumor on blockage beyond the swelling and reduction of size by pressure on the proximal side, if duly considered usıally differentiate them. If deep, especially if situated in an abdomen or thorax of a stout individual, only an exploratory operation or the evidence of delay nay bring a just conelusion, yet the fact that visceral sarcoma often produces fever may aid considerably. (Figs. 9 and 1o.)

Angiosarcoma is not a congenital growtl. Cavernous angiona in most cases is congenital and so shows up at an earlier average age than angiosareoma, even though it may not show up until some time after birth, yet angomata may come in the old. Dubreuilly and Paul Broca have discussed at some length the angiomata that oceur in the skin of old people. They are known as senile angiomata and, Broca says, increase in frequency with age. They do not coneern us here. However, there is another type of angioma called traumatic angioma, which may be confusing, in the light of the faet that sareoma so often is preecded by injury. These angiomata

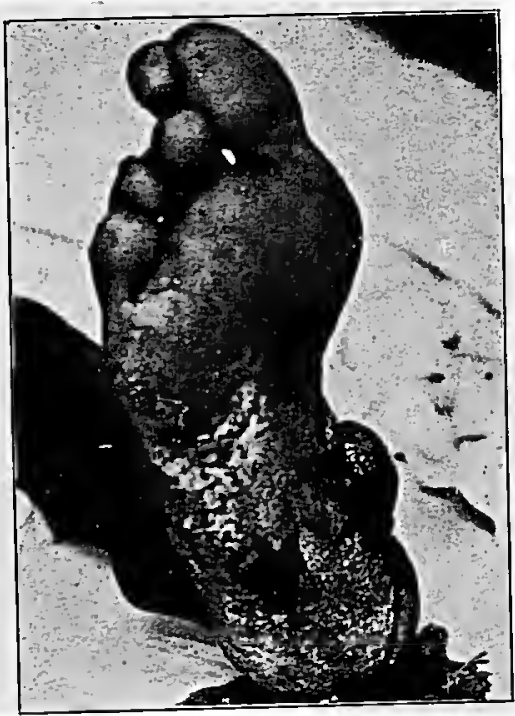

Frc.8-1arge round-celled melnaotie sarcoma of foot. Negro man. age 46 . This tamor developed in a cicatrix following a cut in 1905 , and showed lts first sleas elight months nea.

follow either contusions or repeated and prolonged friction. In these cases the rate of development and the mieroscopical findings will give the only reliable proof. The latter are found eliefly in the subeutaneous and intermnseular tissue. They grow very rapidly and owing to their enormous blood supply, often pulsate vigorously. They are not encapsulated even from the beginning. 